\title{
Re-establishing the Relationship between Urban Structure \& Humanizing Aspects of Indian Cities After the Covid-19 Pandemic: The Case of Delhi, India
}

\author{
Netal Subhash Chandak, Harshwardhan P. Nagpure \\ Institute of Design Education and Architectural Studies (IDEAS), Nagpur, \\ Maharashtra, India. \\ Corresponding Author: Netal Subhash Chandak: E-mail-netal.chandak4@gmail.com
}

\begin{abstract}
Cities are dynamic and liveable places where people experience the phenomenon of life. The essence of Indian cities lies in the interrelationships between urban structure and human aspirations. Urban structure is not just the sum of development blocks, built entities, open spaces, streets and landscapes. It is a set of socio-cultural integration the inhabitants develop. COVID-19 affected urban structures by eliminating humanizing aspects to sustain life. The fundamentals of social integration: place making, flexibility and character, which together shape up the city are under stress. The pandemic has undermined the roots of humanizing aspects in shaping the urban structure as the key urban form determinant. Depending upon urban ways of life, during the pandemic, people have carved their own ways to sustain life. It has sparked a concern about how urban structure will remain humanized by tackling the contradicting values like social disconnection and community disintegration to enrich and enliven the new normal.

This paper examines the case of capital of India, Delhi which has undergone a major shift during the pandemic. It deciphers the consequences of the Covid-19 pandemic on humanizing aspects of Delhi by doing a comparative analysis between the compact and standard prototype of urban structure. First, the study adopts an investigative approach to record, document and analyse the impact on existing urban structure by examining their prototype. Then through physical observations, photographs and documentary evidences, it provides a toolkit useful for re-establishing and shaping the urban structures as humanized urban structures in making a resilient future.
\end{abstract}

Keywords: Urban structures, Humanizing cities, Urban life, Impact of Covid-19, Humanized urban structure, Delhi.

\section{Introduction}

"The city is, rather, a state of mind, a body of customs and traditions, and of the organized attitudes and sentiments that inhere in these customs and are transmitted with this tradition. The city is not, in other words, merely a physical mechanism and an artificial construction. It is involved in the vital processes of the people who compose it; it is a product of nature, and particularly of human nature"

(Park, Burgess \& McKenzie 1925, p. 499 ). 
This definition of Robert Park states how humanizing aspects shape and build the cities. In India, cities evolve by virtue of social interaction, public realms, community participation, multiple users and multi-functional spaces which have enhanced the quality of life by making cities as a humane model. The degree of accessibility and connectivity within such a dynamic and diversified model is defined by its urban structure. It is not just the sum of development blocks, built entities, and open and landscape spaces; it's a set of socio-cultural integrations their inhabitants develop. In the battle against COVID-19 pandemic, multi-dimensional responses such as adhering to social-distancing norms, wearing masks, and hygiene measures have defined a new normal as a tool for survival. These new normal practices have completely isolated people from the welfare of society, further segregating them in economic enclaves by interrogating the effectiveness of governance. The conventional distinction between urban structures depend upon the urban tissue, urban form, land use and density, floating different degrees of responses to practice social distancing. However, people have carved their own ways and methods depending upon urbanism (urban way of life). A great contrast in the approaches towards the pandemic has been perceived between the dense and scattered urban structures within the city in the first half of 2020.These have resulted into drastic and dire changes within urban structures which have hampered the qualitative \& quantitative aspects of life at a major scale. Humanizing aspects being the crucial elements in urban structures, these shape the cities. They need to be critically looked at to enrich and enliven life within the cities.

The intention of this study is to decipher how urban structures which is a diversified model of socio-cultural relationships, remain humanized by uniting the compatibility between the qualitative and quantitative attributes of places. First, the study maps and analyses the impact of the Corona virus disease on the existing urban structure. Then it will re-establish and shape the void between the humanizing aspects and urban structures to make humanized urban structure as a combating model within such inevitable pandemics.

\section{Background}

In India, cities are perceived by the diversified assets of its people's beliefs, aspirations and desires over religious, political and socio-cultural ethos, which intervene into the disparity between planned and organic sprawl of the city. Delhi is one of the oldest cosmopolitan cities, which amalgamates such footprints of planned and organic sprawl. The population of Delhi was 16.8 million in 2011 with $97.5 \%$ living in an urban area of 1483 sq. kms, having a population density of 11,297 (range $3800-37,346 / \mathrm{km}$. sq. $)^{1}$. It is important to note that the city has been reformed many times to become the dominant capital. Two important constituents which shape the urban form of the city are: Old Delhi and New Delhi which are segregated by the Fortified Wall and Ramlila Maidan. Old Delhi - Shahjahanabad, built by the Mughal Emperor Shah Jahan, has a compact urban fabric with a high amount of socio-cultural relations. The spatial hierarchical organization in terms of Mohalla as a neighbourhood blocks consisting of small lanes termed as kutchas, gali, katras, nukkad has allowed the diversification of living contributing to humanization. On the other hand, New Delhi was built next to Shahjahanabad as the capital of British India. There, the urban tissue is scattered and is highly developed in terms of its infrastructure enhancing the quality of life. Thus, Delhi is a result of a strong amalgamation of contradicting urban morphologies which have their own aesthetics and identities. Here, urban structure engenders the city with a distinctive pattern of human correlations. Presently, in the month of September 2020, Delhi has been predicted as the second hotspot city in the country affected by COVID-19 with 2,30,000 total cases recorded (Covid 19.org.Delhi,2020). The conventional distinction between Chandni Chowk in Shahjahanabad as a compact urban structure

\footnotetext{
${ }^{1}$ https://knowindia.gov.in/states-uts/government-of-nct-of-delhi.php
} 
and Connaught Place in New Delhi as a standard urban structure has found its own way of dealing with the COVID-19. The Delhi government implemented the prestigious project of Primary Health Care centres through "Mohalla Cliniques". Looking towards the wide-spread effect of pandemics, the government authorities transformed the 'Mohalla Cliniques' as the main anchor points for contact tracing to address the pandemic. 480 such units were transformed to facilitate people with better services (The Hindu, 2020). The pandemic has altered the situation of Delhi where the process of formation and transformation within the urban grain has reset the definition of the humanizing aspect of Delhi: its people and places. Therefore, this research identifies the impact of the pandemic on the imperative elements within the urban structures driven by the humanizing aspects of the city. The essence of Indian cities lies in humanized urban structures, which channel the differences of their spatial forms, relationships and characteristics. Social interaction, cultural ethos, multi-faceted community participation, conglomeration and hustle bustle of the people in the public realm are important parameters which may improve humanization of the city.

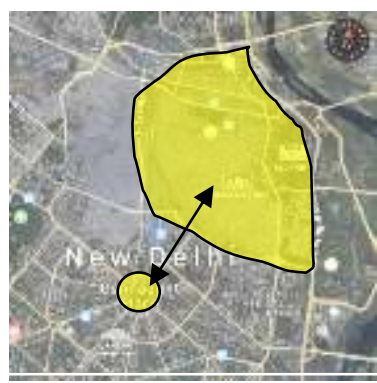

Fig. 1: Connection between Chandni Chowk in Shahjanabad and Connaught Place in New Delhi Source: Google maps

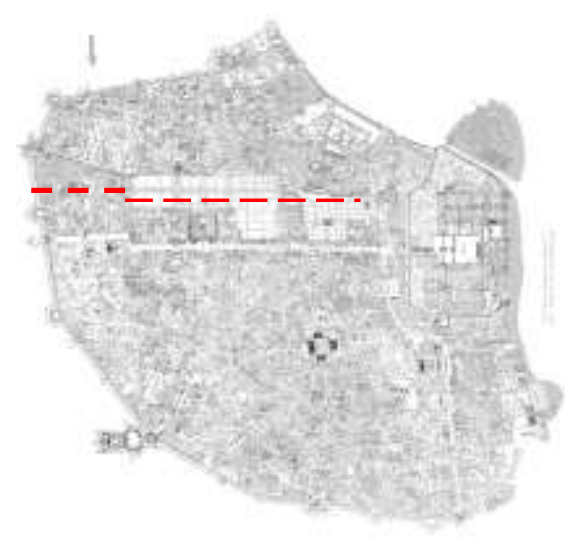

Fig. 2: Layout plan of Chandani Chowk Source: Author

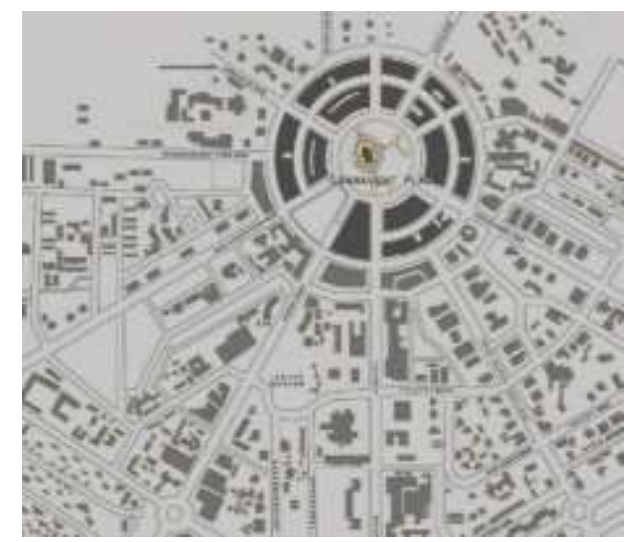

Fig. 3: Layout plan of Connaught Place Source: Author

\section{The Theoretical Framework}

Urban structure is the arrangement of land use in urban areas. In other words, it is how the land use of a city is set out. It also refers to urban spatial structure, which concerns the arrangement of public and private spaces in cities and the degree of connectivity and accessibility. The term urban structure refers to the pattern or arrangement of development blocks, streets, 
buildings, open spaces and landscapes which make up urban areas. It is the interrelationships between all these elements rather than particular characteristics that binds them together to make place (Llewelyn-Davies 2000).

The city, and particularly the great city, in which more than elsewhere human relation is likely to be impersonal and rational, defined in terms of interest and in term of cash, is a very real sense a laboratory for investigation of collective behaviour (Park, Burgess \& McKenzie 1925). If we look at the history of cities, we can see clearly that urban structures and planning influence human behaviour and the ways in which cities operate. If there is life and activity in city space, there are also many social exchanges. If city space is desolate and empty, nothing happens (Gehl 2010).

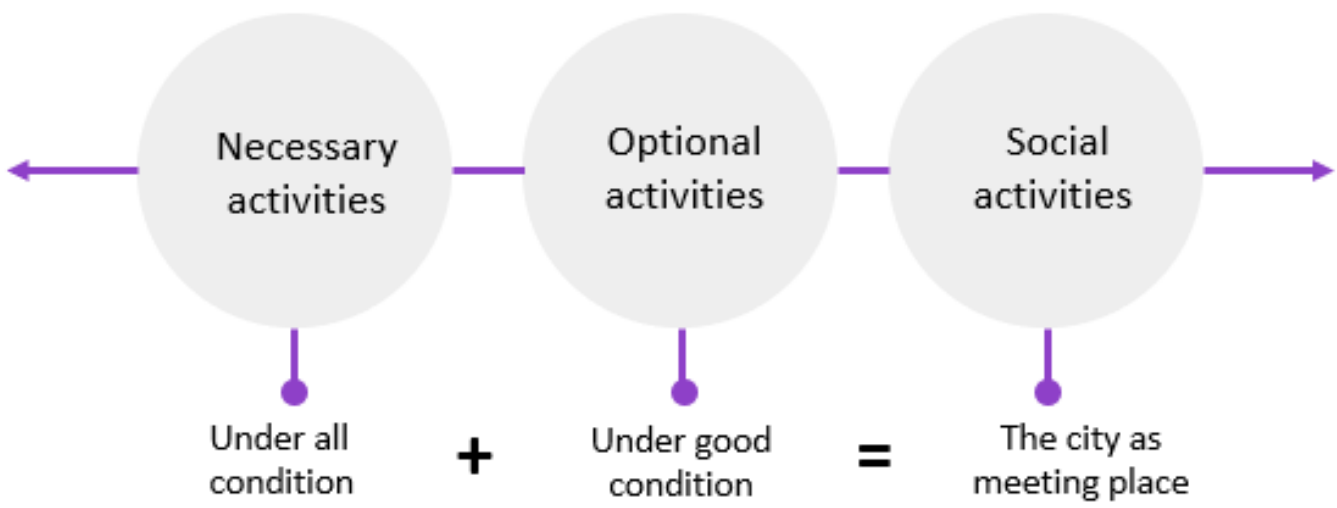

Fig. 4: Types of activities

Source: Gehl, 2010

On the basis of the degree of necessity, Gehl has categorized three types of activities. Necessary activities are purposeful, non-optional part of everyday life. These activities take place under all conditions, which have no choices. Optional activities are recreational and fun. These activities take place under good conditions, for which good city quality is a pre-requisite. Social activities include all types of contacts between people and take place everywhere people go in city space.

\section{Defining Urban Structure and Humanizing Aspects in India}

Urban structure is everything that surrounds or occurs at a particular place and time. People can facilitate a successful network of dialogue, recreation and interactions within this urban existence to make an environment humane. The nature and behaviours of urban structure is an interconnected and interdependent complex process of all the tangible and intangible attributes at micro and macro scales which generate a harmony within a city. It's a homo-hetero organization resulting in the diversification of socio-cultural relationships, beliefs and aspirations among people, though acting as one whole composite system making an organization more humanized.

\section{Prototypes of Urban Structure in Indian context:}

A clear core prototype of urban structure emerges from the great diversity of urban fabric and urban forms in city space. Depending on the basis of urban fabric, which contributes to the degree of urbanism, urban structure is largely categorized into two types: compact urban structure and standard urban structure. 
1. Compact urban structure: Compact cities have affected and give shapes to urban form directly, which support essentially developments in vertical and high-density built environments. It is a complex system where urban environment is composed of various interconnected and inter-dependent elements of the built-environment. It belongs to a setting which has organic and dense urban fabric facilitating urban life directly. The typical characteristics of a compact urban structure has a significant consequence on public activity, with high diversification of users, which keeps the city lively and amicable. Living in a compact urban structure allows great opportunities for socio-cultural interaction with safety and security. Walkable neighbourhoods and mixed land use provide a great scope for jobs and work. This is how valuable associations between a physical entity and non-physical attributes of people contribute in shaping a humanized city.

2. Standard urban structure: Generally, these structures belong to newer settlements of a city which carries a strong assimilation of infrastructurally developed standard urban components like shopping malls, parks, residential cores and subdivisions which enhance the quality of life of inhabitants. It is a scattered multi-centred model with a distinct urban fabric which allows comprehension and easy recognition. Standard urban structures are typified as lowdensity development with interrelated socio-cultural and economic forces. The close connection between physical and social dimension within a well-defined coherent network contribute in shaping a humanized city. methodology adopted for this paper is an attempt to understand and analyse the impact of the COVID-19 on urban structure by deciphering the imperative elements of humanised urban structure. The study was carried out by non-physical means; by remotely conducting online surveys of local people and also by observing, analysing, and anticipating the existing scenario. It employs a case study approach and investigates a comparative study between compact and standard prototypes of urban structure.

\section{Research Methodology}

The methodology adopted for this paper is an attempt to understand and analyse the impact of the COVID-19 on urban structure by deciphering the imperative elements of humanised urban structure. The study was carried out by non-physical means; by remotely conducting online surveys of local people and also by observing, analysing, and anticipating the existing scenario. It employs a case study approach and investigates a comparative study between compact and standard prototypes of urban structure.

Fig. 4. represents the methodology adopted to conduct the research. It provides a theoretically supported and practice-based study, analysed into three fragments: tracing the past, analysing the present and originating the future. 


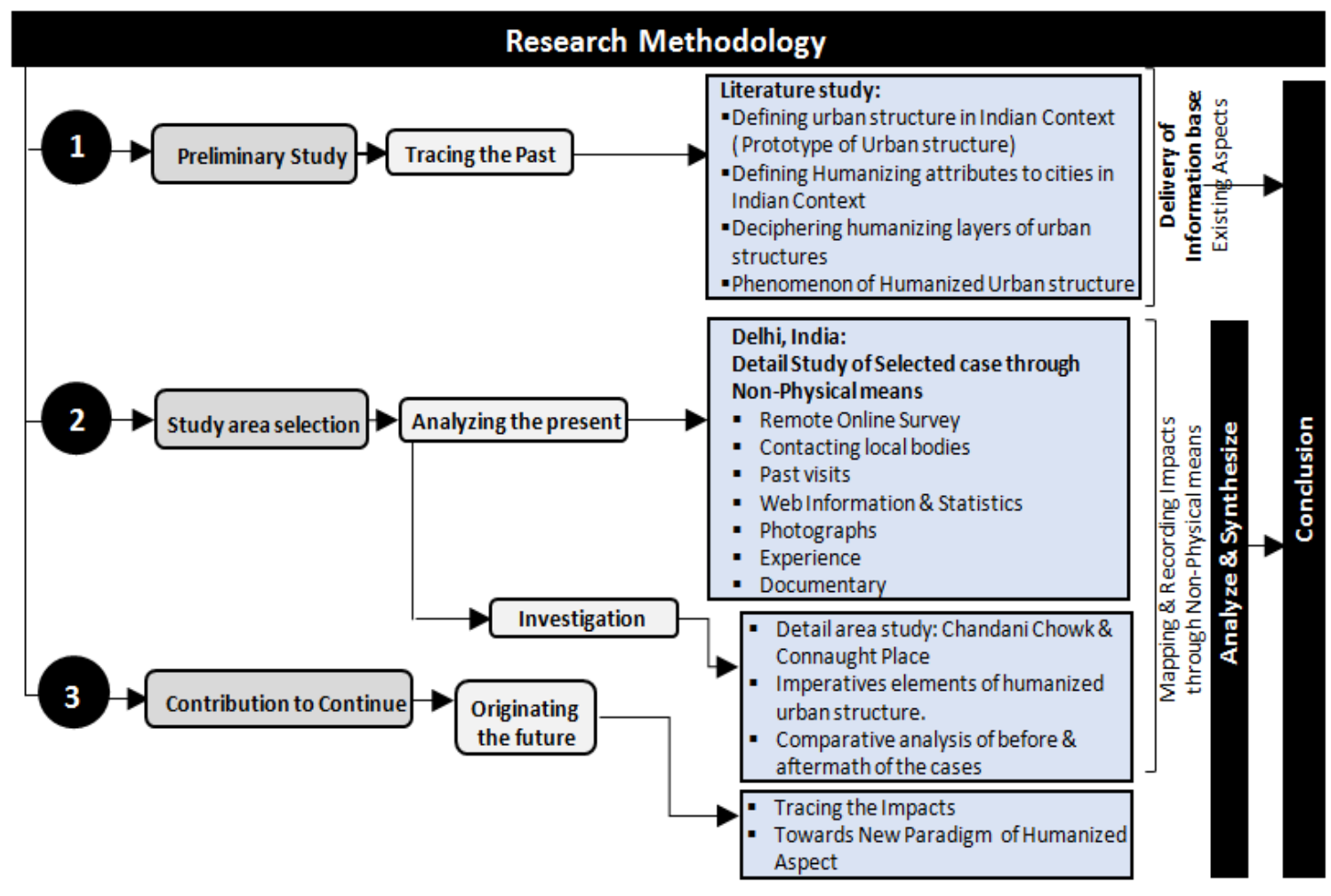

Fig. 5: Research methodology

Source: Author

\section{Deciphering the Humanizing Layers of Urban Structure}

The composition of an urban structure generates a place for different individuals coming together as a common aspect to perform an activity and experience the place. It directly or indirectly assimilates multiple minds engaged in multi-faceted activities set in public and private spaces in the city. The strong relationships of users with any urban component (street, open space, building, etc.) helps to encourage public activities and generates active public realms which strengthens the sense of place.

Depending on the practice and functioning of the activities, inhabitants share a very close co-existence which can be classified into three layers which contribute to a humanized urban structure.

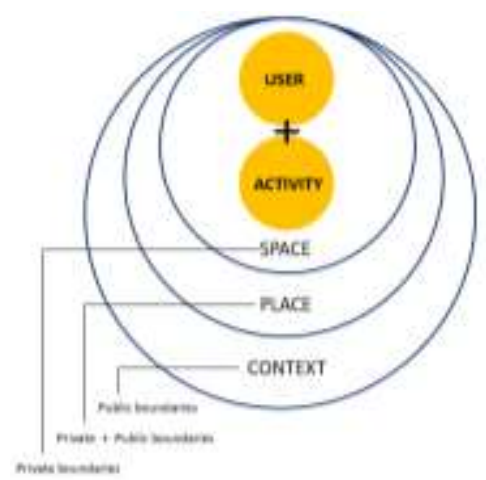

Fig. 6: Layers of urban structure Source: Author 


\section{Layer 1: User-Activity-Space}

It refers to a set of disciplines where constituent elements of an urban structure are perceived individually. It is in direct-relation to the users with its definite activity enhancing the private boundaries of space. The close connection between people and space contributes to necessary dimensions of the activity.

\section{Layer 2: User-Activity-Place}

It integrates socio-cultural relations which develop a coherent framework to quantify aspects of urban structure. It is an intra-relation of users with its definite activities enhancing the public and private boundaries of a place. The close connection between people and places contribute to the moral dimension of activity.

\section{Layer 3: User-Activity-Context}

It is a multi-faceted urban existence, which has the capacity to evolve by respecting existing values which generates a context. It is an inter-relation of users with its definite activity enhancing the public boundaries of urban structure within its context. The close connection between people and the context contribute to social dimension of activity.

\section{Phenomenon of Humanized Urban Structures}

The phenomenon of a humanized urban structure generates a coherent framework of tangible and intangible attributes respecting the diversity and multiplicity of users. Further, it determines various layers depending upon the intensity and degree of association with respect to activities. The tangible attributes of an urban structure are physical entities in the form of a street, an open space, buildings etc. whereas intangibles attributes such as socio-cultural interactions, conversations, meetings, recreation, etc. contribute to the human aspects of a city. The characteristics of urban tissue differs according to the prototype of the urban structure developed on the basis of identity, social integration, accessibility and place making.

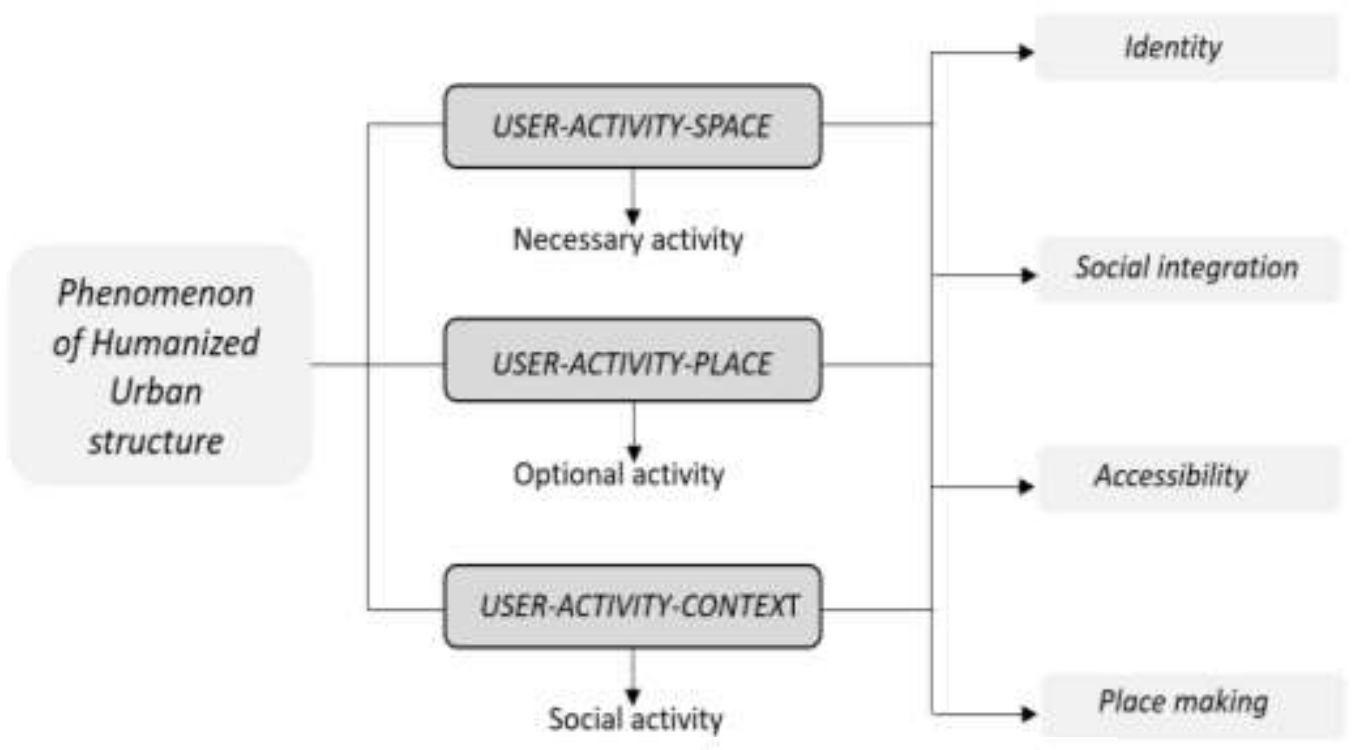

Fig. 7: Phenomenon of humanized urban structure Source: author 


\section{Case Study-Delhi}

Covid-19 has completely transformed Delhi from a cosmopolitan ethos to a sophisticated model, which has detached people from the welfare of the society. Earlier, the humanized essence of Delhi was in active street life, diversified and mix-use of users and activities, socio-cultural interaction and relationships, which has been hampered significantly because of the pandemic. The damage of the urban structures that has generated environmental stress, has been noticed on people's behaviours, cognitive functions, physical health and lifestyles which were coping with various phases of the disease.

\section{Detail Area of Study}

a) Chandni Chowk: It is a compact urban structure where the strong socio-cultural relationships in mohalla, kutchas, gali, katras almost disappeared and the economy has been severely disrupted as it is one of the largest economic hubs of the city and the Nation.

b) Connaught Place: It is a standard urban structure where huge community spaces, amenity spaces and club houses became suddenly unusable. There was a complete social disconnection which has hampered the dignity of such a premium location.

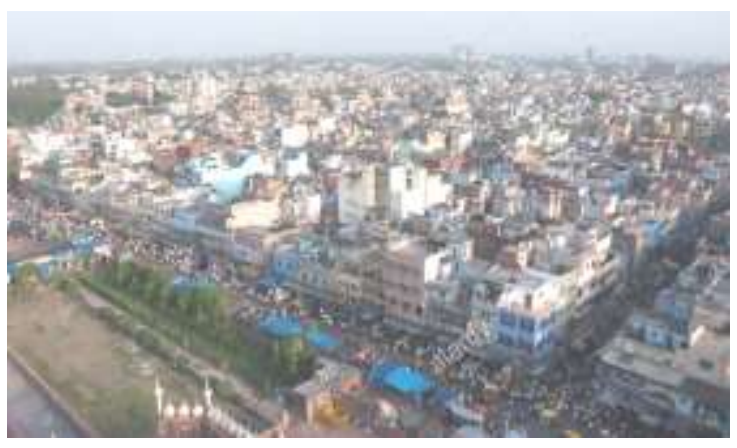

Fig. 8: Chandni Chowk, old Delhi Source: Alamy

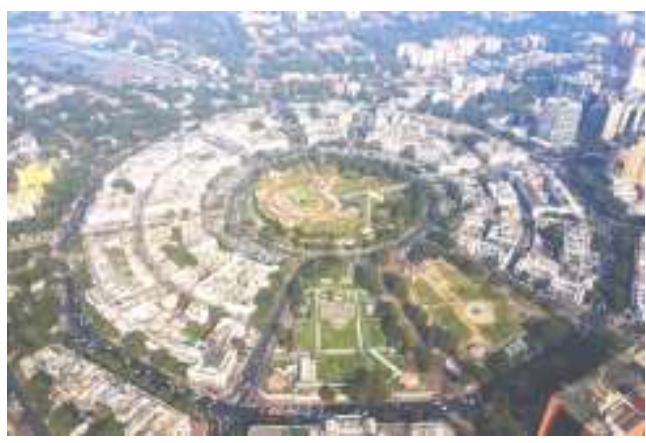

Fig. 9: Connaught Place, New DelhiSource: The telegraph

\section{Imperative Elements of Humanized Urban Structure and Impact on Delhi}

Delhi has evolved over a period of time as an integration of social spaces; a dynamic module that has amalgamated varied communities \& has enhanced quality of life. The social spaces: parks, streets, squares and promenades are the focal points of urban structure, where exchange of idea, communication, and interaction makes the environment more amicable and humane. Depending upon the physical structures and their moral aspects, which connect people in every aspect of live are: identity, social integration, flexibility and placemaking. They are the imperative elements which trigger the symbiotic relationship of Humanization within the urban structure. The humanization parameter generated by virtue of this imperative elements help strengthen the quality life by connecting them together to dissolve any social barriers within the society. However, COVID-19 has drastically changed the pattern in which we navigate our urban life. Transmulation in the configuration of urban activities and its approaches has generated an unacquainted environment. In Delhi, COVID-19 has transformed the urban structure, which became more a mechanical, rigid and congruent model defining the cities as a machine. It is high time to control the change for a resilient future. 
Table 1: Theoretical Framework: Impact of COVID-19 on Imperative elements of humanized urban structure in Delhi. Source: author

\begin{tabular}{|c|c|c|}
\hline $\begin{array}{l}\text { Imperative elements of } \\
\text { Humanized urban structure }\end{array}$ & $\begin{array}{l}\text { Humanization } \\
\text { Parameters }\end{array}$ & Impact of covid-19 \\
\hline Identity & $\begin{array}{c}\text { Character } \\
\text { Dynamic Density }\end{array}$ & $\begin{array}{l}\text { Loss in street identity } \\
\text { Decline function } \\
\text { of dynamic density }\end{array}$ \\
\hline $\begin{array}{c}\text { Social } \\
\text { integration }\end{array}$ & $\begin{array}{l}\text { Human co-relation } \\
\text { Participation Approaches }\end{array}$ & $\begin{array}{l}\text { Confined Human co-relation } \\
\text { Utilitarian approaches }\end{array}$ \\
\hline Flexibility & $\begin{array}{l}\text { Urban social mobility } \\
\text { Urban display }\end{array}$ & $\begin{array}{l}\text { Redefined pattern of } \\
\text { urban social mobility }\end{array}$ \\
\hline Placemaking & $\begin{array}{l}\text { Public Realms } \\
\text { Social Hife }\end{array}$ & $\begin{array}{l}\text { Alteration in Public realm } \\
\text { Downturn of social life }\end{array}$ \\
\hline
\end{tabular}

\section{Impacts in Delhi: Case-A Chandani Chowk \& Case-B Connaught Place}

\section{Loss of Street Identity \\ Case A}

Before the Pandemic: In the past, the streets in Chandni Chowk were highly congested, around one hundred thousand people visited the old city core to address various supply chain industries establishing a symbiotic relationship between the needs and demands interwoven with commerce. In addition, because of the compact and dense behaviors of streets, walking, cycling and biking are the predominant modes to commute. Here, streets are largely supported with the juxtaposition of ritual activities, processions along markets which render the activities forming collective identity of the street. The interrelated and interdependent cyclic processes of activities generate an urban crowd giving a unique character and identity to its urban structure.

During the Pandemic: This completely altered the daily drama of life that unfolds the rich urban setting by floating norms like social distancing, and lockdown which have changed the fundamentals of participation, access and quality life within the streets. The central spine of Chandni Chowk is largely a pedestrianized commercial street which has been transformed into a deserted lane during the lockdown with no people and life. Gradually, when people were coming back to their normal life, active participation in the commercial activities was traced to fulfill their necessary needs and demands with a contrast and different behavior resulting into a loss of street identity. Fig.10. shows the impact of pandemic which has slackened the character and identity of the Chandni Chowk Street. 

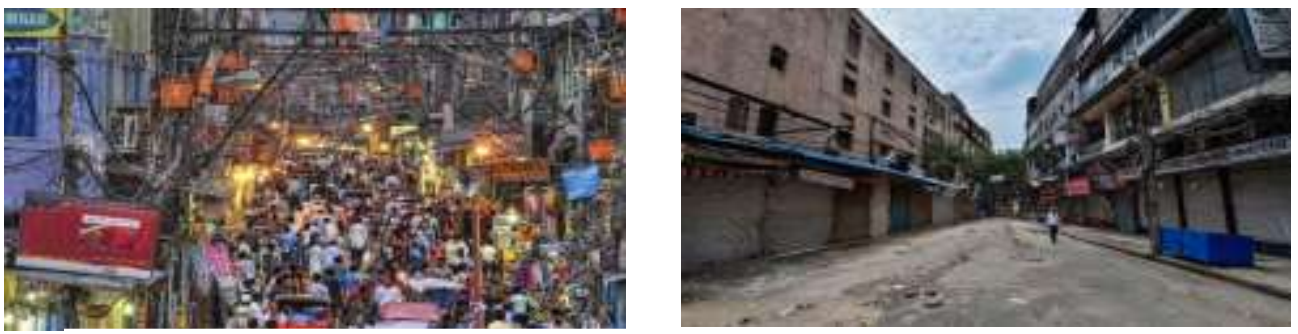

Fig. 10: The Street of Chandni Chowk before \& after pandemic Source: The telegraph

\section{Case B}

Before the Pandemic: Connaught Place is ideally categorized for its great motif, locale and ideology which carry a layer of values and associations of people with activities within the place. Sidewalk of the shopping stretch has always remained articulated with an influx of pedestrians making the place lively. Street furniture were the great anchors for the public realms to attract people which has shaped the identity of the street.

During the Pandemic: During the phase of lockdown, the association with this great place has vanished completely resulting into a dead urban void. The huge structure meant for the commercial purpose suddenly became a deserted place due to the lockdown impositions. The loss of pedestrians and deteriorating informal commerce on the stretch of street has questioned the longevity of identity. Fig. $11 \& 12$. Show that the impact of the pandemic has declined the character and identity of Connaught Place.
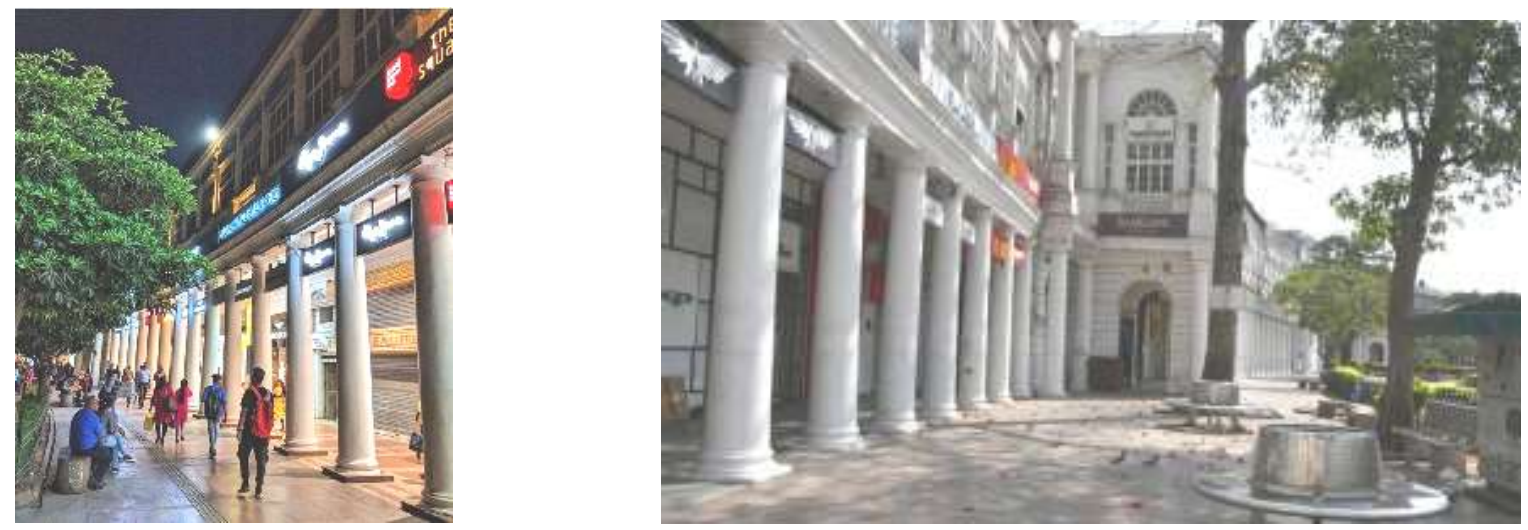

Fig. 11 \& 12: Connaught Place before \& after pandemic Source: Google

\section{Decline in the Function of Dynamic Density}

Density is categorized into material and dynamic density. Material density is the population density, which is the ratio of people to land whereas the dynamic density is the rate of interaction within a population (Durkhein 1949). ${ }^{2}$

\footnotetext{
${ }^{2}$ https://www.encyclopedia.com/social-sciences/dictionaries-thesauruses-pictures-and-press-releases/dynamicdensity
}

'Cities People Places': an International Journal on Urban Environments Centre for Cities, University of Moratuwa, Sri Lanka. 
If one visualises a humanized city, vital features which contribute to humanization is the ratio of dyamic density. Greater dyamic density contributes to a greater humanized structure. The pattern in which people interact with other people faciltates in creating social cohernce.

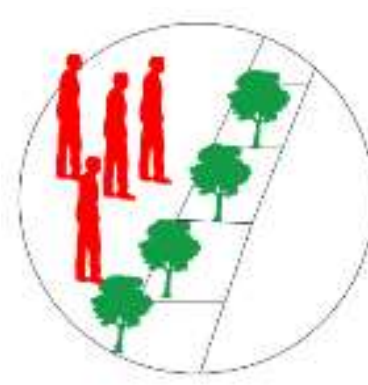

Material density

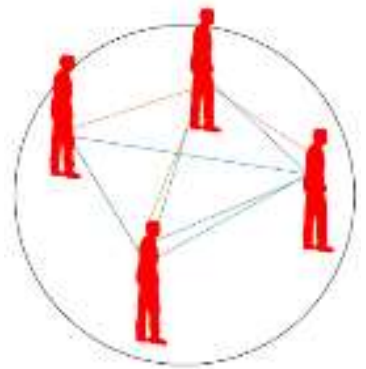

Dynamic density

Fig. 13. Types of density

Source: Author

\section{Case A}

Before the Pandemic: The paucity of space and overcrowded population in apropos of commercial gain, it has generated a dense network of social interactions which has uplifted the dynamic density. By virtue of the high ratio to dynamic density, Chandni Chowk has emerged as a ceremonial axis with high interaction and social connection enhancing the human life within the city.

During the Pandemic: COVID-19 pointedly impacted the dynamic density by drooping huge numbers of people who use to move, sit, interact and recreate a dialogue within the place. However, because of the inherent commercial quality of place, the material density is not much affected but dynamic density that has taken a step down in order to maintain social disconnection as a need of the time. Decline in functioning of dynamic density has hampered dynamism, which arises from daily chaos that unfolds the rich urban setting.

\section{Case B}

Before the Pandemic: Connaught Place being the scattered urban fabric facilitated with huge open spaces, streets, landscaped spaces, podiums and terraces in buildings allows high interaction with socio-cultural and political gains. Here, people enjoy social life, which has enhanced the dynamic density.

During the Pandemic: Connaught Place has a major loss on the sense of belonging and the degree of intimacy within the urban structure. The emergence of passive community participation has formulated dynamic density as a notional norm in the dictionary of humanizing city. Social disconnection, community disintegration, lack of daily interaction are the methods adopted in the new normal which have produced a spatial difference in social behaviour. Approaches such as solitude, isolation and self-centricity have questioned the concept of dynamic density.

\section{Confined Human Correlation}

\section{Case A}

Before the Pandemic: In Chandni Chowk, during the active hours, commercial functions and flexibility in terms of accessibility govern the human correlations in the urban structure. The degree of intensity generated contributes to humanization and sociability of the place. 
During the Pandemic: Due to the compact urban structure, people were finding it difficulties to adhere social distancing norms. Urban life finds a new form and approach to strengthen the network of accessibility within confined and consolidated human associations. Commercial frontages through selling and display of items is now superficial and govern the transit interaction.

\section{Case B}

Before the Pandemic: People availed themselves to all kind of activities within the urban structure. Here, built environments generate external spaces where informal commerce fulfils the demand of the common people. However, it amalgamates informality with premium and standard arrangements generating flexibility within the users by removing the boundary of the sociocultural differences resulting in diversity and co-relation.

During the Pandemic: COVID -19 pandemic has altered human co-relations within both formal and impersonal settings embedded into threats of physical contact. The functioning has transformed depending upon the degree of intensity of the people to cater the changing needs of the place. Most parts of the sidewalk which used to be filled with hawkers and vendors has declined the daily ritual in the structure by making confined boundaries around the users depending upon class defined by the economic status.
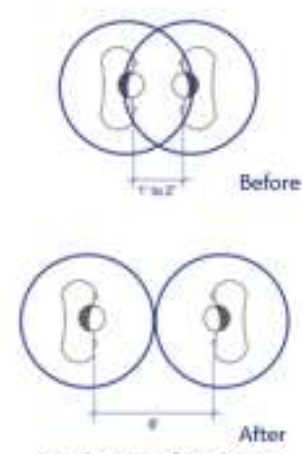

Personal space
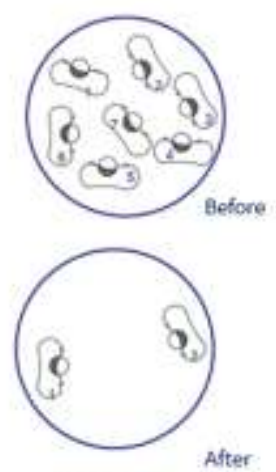

Crowd
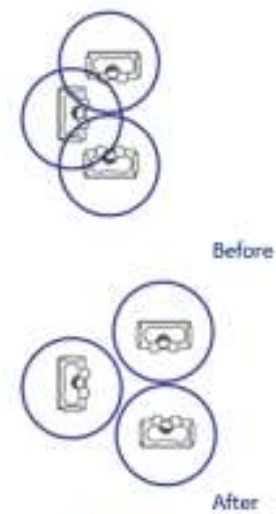

Sitting
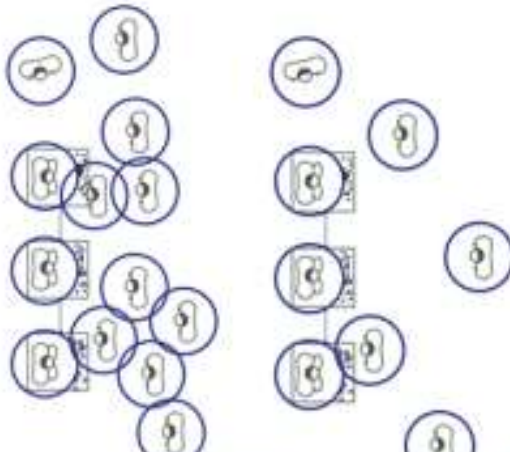

sefore

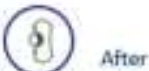

Gazing at curbs or at vendors

Fig. 14: Comparative analysis of human correlation before and after COVID-19.

Source: author

\section{Utilitarian Approaches}

\section{Case A}

Before the Pandemic: Utilitarian practices refer to an association which is more oriented towards potential gain rather than intrinsic satisfaction. When used in a socio-political construct, utilitarian ethics aim for the betterment of society as a whole. ${ }^{3}$ In the past, Chandni Chowk and Connaught Place were a realm with active people's participation.

During the Pandemic: Human interaction has become actionable rather than sentimental and amicable. Aggregative, unitary and deontic approaches have proven to be as central actions of public interests. People have adopted different approaches in public spaces to buy from street vendors. Fig. 9. shows that the people waiting in a queue a few meters apart due to the new kind of physical interaction alter the rhythm of urban life within the urban structures.

\footnotetext{
${ }^{3}$ https://www.investopedia.com/terms/u/utilitarianism.asp
} 


\section{Case B}

During the Pandemic: During the first phase of the pandemic, informal recreational activities were split from the typical form and character of the fabric. However, during the subsequent phases, a distinctive and segmental human pattern of interaction has emerged, with newer ways of physical interaction. The private and public settings within the urban structure adopted approaches to increase physical interactions by eliminating societal instability. Hence, people have adopted specific patterns which in turn are fulfilling the basic requirements, needs and demands.
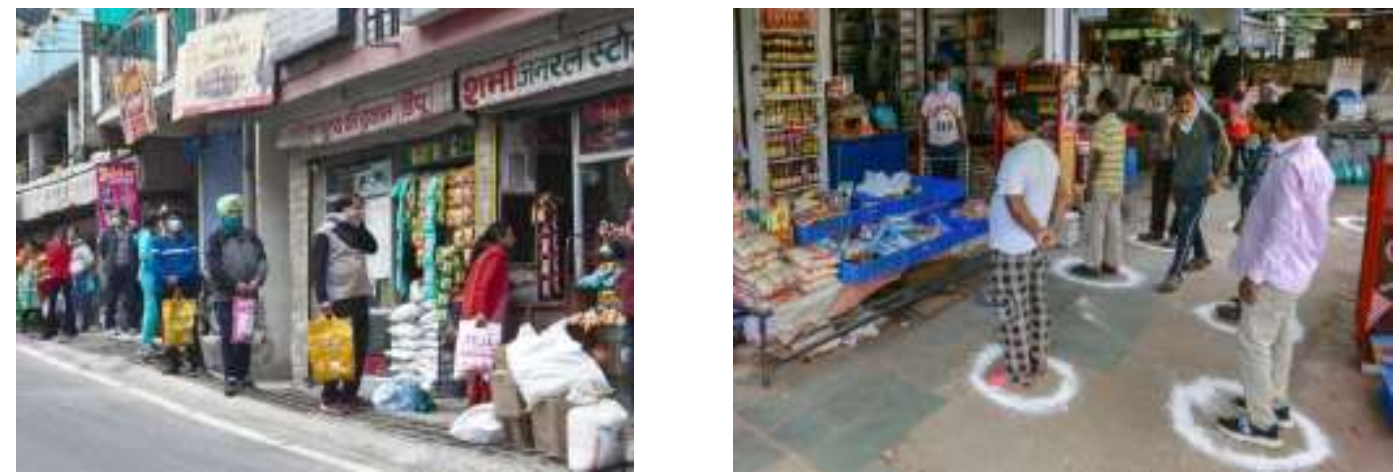

Fig. 15: Utilitarian approach: Defining a New Social Behavioural pattern

\section{Redefining the Pattern of Urban Social Mobility \\ Case A}

During the Pandemic: The essence of compact urban structure lies within the multifarious overlays of formal and informal commerce juxtaposed with a layer of pedestrianization. This association has considerably disappeared due to the restrictions on informal commerce. A continuous addition and modification of policies has governed the entire urban mobility pattern which is shaping the sociability within the place.

\section{Case B}

During the Pandemic: A high decrease in commuting, restrictions on vehicular movement, and the limitations in public transport systems has forced a transformation in social and functional properties. In the standard urban structure, transformation in the mobility pattern has impacted the social relationships and interactions. Approximately 52\% of the population is practicing work from home in order to reduce the degree of exposure. A dramatic decrease in motorization has changed the lifestyle of people completely. The government policies like odd-even patterns have interrupted the outdoor activities generated by the unacquainted environment within urban structure. Reduction of pollution was a positive outcome which has upgraded the environment of Delhi.

\section{Transition in Urban Display \\ Case A}

Before the Pandemic: Chandni Chowk has an informal discipline of vibrancy, aesthetics, inscribed history and hidden intangible attributes of emotions, and attachments within the place. Informal urbanism is the expression of chaos, social life, mixed commerce activities and people creating a pattern which is vibrant in nature. The urban display was an outcome of the close-knit fabric, narrow lanes, gali, and the shaded pathways governing the physical nature enhancing the user experiences. 
During the Pandemic: The lockdown impacted the urban display which resulted into a display of closed shutters with bulky tangible constructs of built-form and no people outside. People have gathered in fear of being a part of such displays in future. It has not only impacted the economy with quality of life but has also questioned the entire pattern of space function the way it was before.

\section{Case B}

Before the Pandemic: Connaught Place was having a strong display of its architectural expression, with formal commerce addressing the high profile users and elite classes enjoying their social life. However, over a period of time, the layer of informal commerce co-existed with the formal. In today's time, the urban display of Connaught Place is multifarious with all types of commerce inviting users of different socio economic classes resulting in creating a place for all.

During the Pandemic: Due to the ban on the informal commerce, the character has diminished with all the multiple layers of urban display having vanished from the character of place. The space exists with a historical built form with no meaning. Due its large scale, it has brought a sense of reluctance among the people to be part of this place. The corridors have become dead alleys and closed shutters.
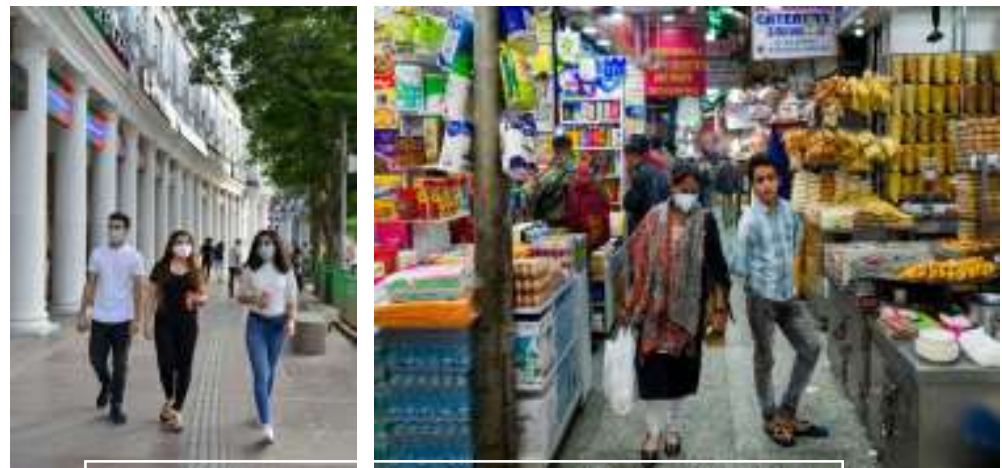

Fig. 16 \& 17: Urban display during pandemic

Source: India tribune

\section{Altering the Public Realm}

Case A

Before the Pandemic: Chandni Chowk is one of the oldest urban public realms within the City. Definition of public realms in Chandni Chowk is a mix of informal commerce with most of its spaces, streets and alleyways pedestrianized, walkable and porous where people enjoy their social life. The realm has a rhythm with limited formal spatial separation of street commerce from vehicular movement with people in between them.

During the Pandemic: Chandni Chowk doesn't carry an image of chaos which was full of thousands of people, hustle and bustle of shopping and vending activities. The entire stretch which was full of active public life before has undergone a reset with an oasis of calm and spiritless space in the city. The place which was filled with people before, their aspirations, and celebration has become lifeless while keeping the public realm a speculative realm of the humanized city. 


\section{Case B}

Before the Pandemic: The iconic shopping and recreational remnant of the colonial Capital has always been full of intense people's participation. Connaught Place is used by multiple people, not just because it's a Business District, but because it is a comfortable place for all the people to use and access enriching its public realm.

During the Pandemic: The pandemic has brought about a contrasting effect in Connaught Place by altering the phenomenon of public realms in the city. The fear of social contact and imposed lockdown has removed many hawkers and vendors, who earlier used to attract huge number of people to be part of the public realm.

\section{Downturn of Social Life}

\section{Case A}

Before the Pandemic: The open nature of place with flexible public character was representation of people's attitudes and beliefs which develops strong social coherence within the place. The compact structure enriches dense spaces by virtue of people participation in typical activities related to religion, political, commercial, and recreation by celebrating their social life.

During the Pandemic: The character of people participating has shifted to minimal function and meeting point by removing the essence of urban social life. The decline in the coherence and involvement of strong social activity has entirely disconnected people with their socio-urban environment.

\section{Case B}

Before the Pandemic: It was an inclusive and developed place with multi-functional spaces and activities, addressing to multiple users. This attracted various users from varied economic groups, castes, culture and religion to be part of the place uplifting the social character.

During the Pandemic: Closure of restaurants, theaters and shops have reversed the economy and has resulted in a financial downfall. Interruptions in celebrations and festivals has transformed normal social life. The place has lost its vibrancy disrupting the social algorithms. It has entirely removed the traces of people, commerce and social inclusions losing its identity.

\section{Comparative Analysis between the Prototypes}

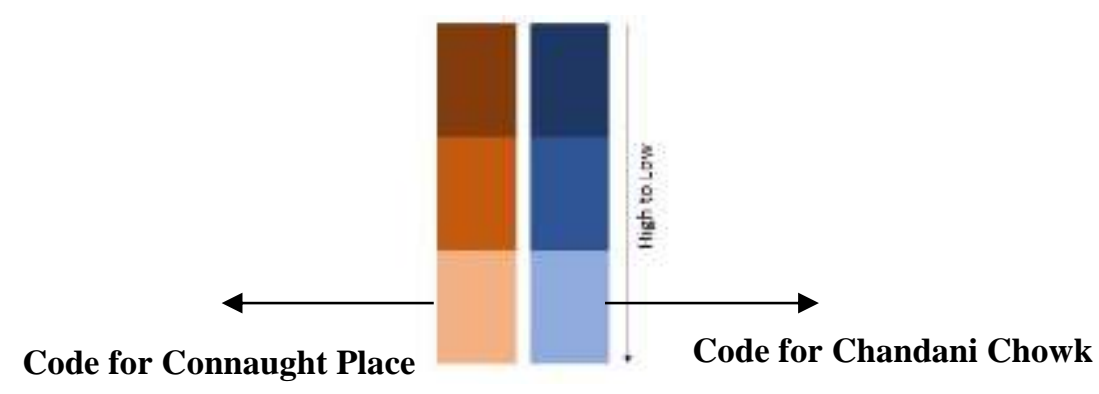

Fig. 18: Code denoting diagram

Source: Author 
Table 2: Chart showing comparative analysis at different scales for various parameters, before and during the Pandemic.

Source: Author

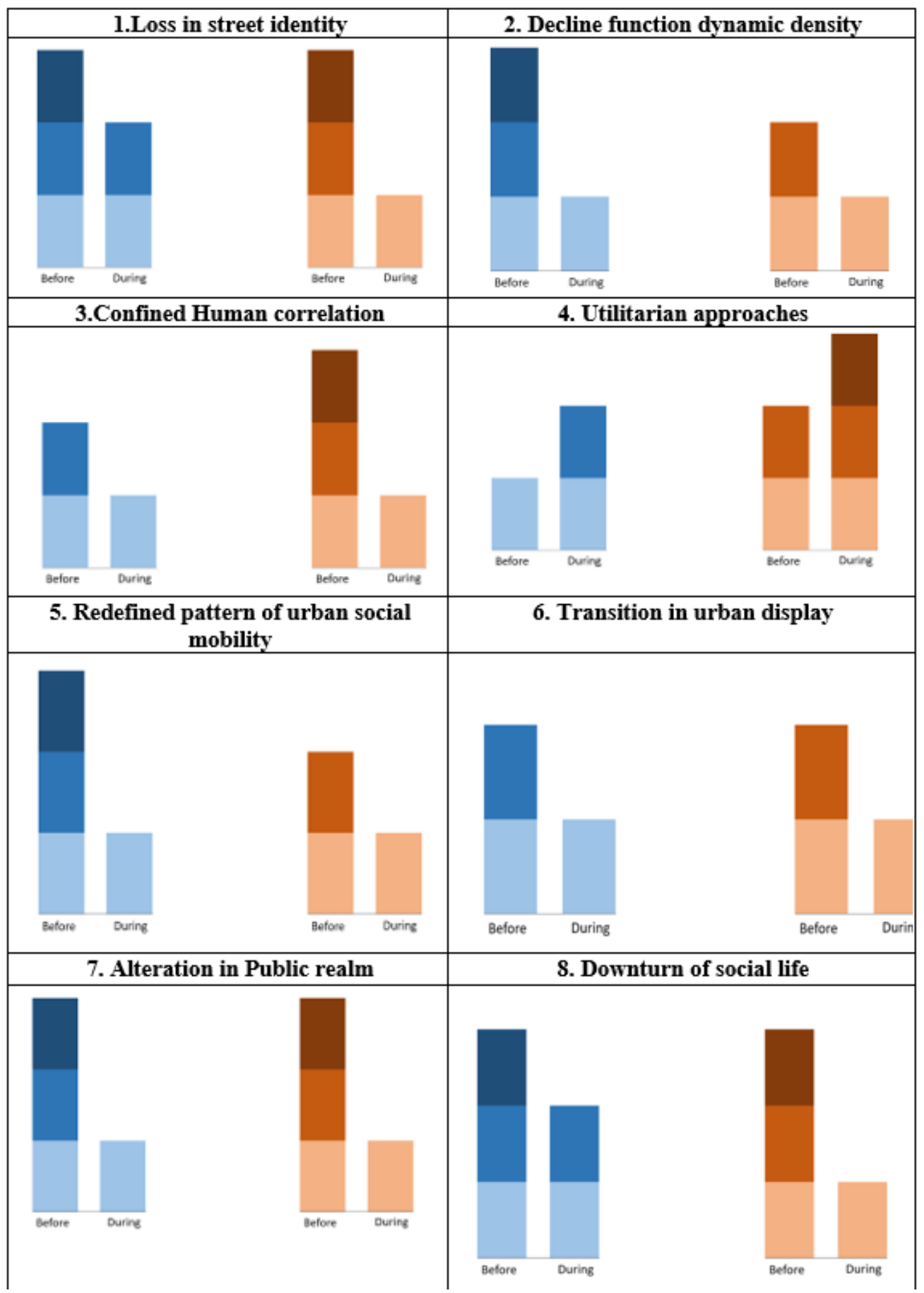




\section{a) Compact urban structure}

Chandni Chowk acts as a ceremonial axis which converges varied social and economic connections in a dense urban structure. Because of paucity and narrow roads with informal interaction spaces, social distancing has been almost impossible. Physical realities pose a high degree of exposure as the arrangement of land use is dense and compact. It has upsurges in the rates of transmission of infection. Round the clock multi-functionality of compact urban structure poses challenge, facing higher contact threats creating a dilemma. The setup suffered strong social stratification in Mohalla's where sense of belonging was under constant devastation and eviction process. Practising work from home was almost impossible due to lack of resources and technological advancements, throwing challenges in order to adhere to the social distancing norms. The entire urban structure is multifunctional and is a mixed-use fabric where depending upon the hierarchy of spaces, the public and private boundaries amalgamate. Such diversified boundaries have experienced a great shift in order to maintain social disconnection and community disintegration.
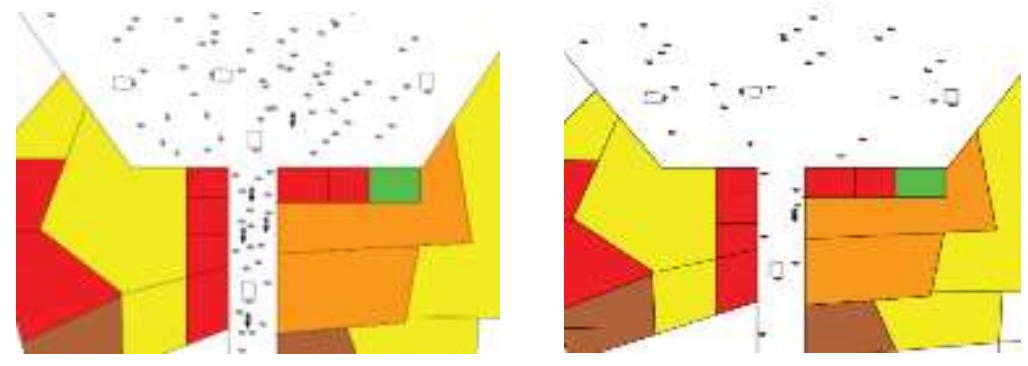

Fig. 19: Before and after scenario of COVID-19 in Chandni Chowk. Source: Author

\section{b) Standard urban structure}

In Connaught place, there were no major changes in the surrounding as social distancing was flexible and easy to adopt because of scattered developments. The standard urban structure allowed people to facilitate themselves with great health care services. Curative measures for COVID-19 Patients were possible at home through home-quarantine practices. Open \& Semi Open Spaces allowed isolation, where the degree of exposure is less. However, huge structures of community spaces, club houses and amenities became obsolete. Open spaces remained unattended deteriorating social life. A major contract in the lifestyle has been when work-from-home acted as a tool kit to practice isolation. However, because of the careless attitude and carelessness of people the virus spread wisely.
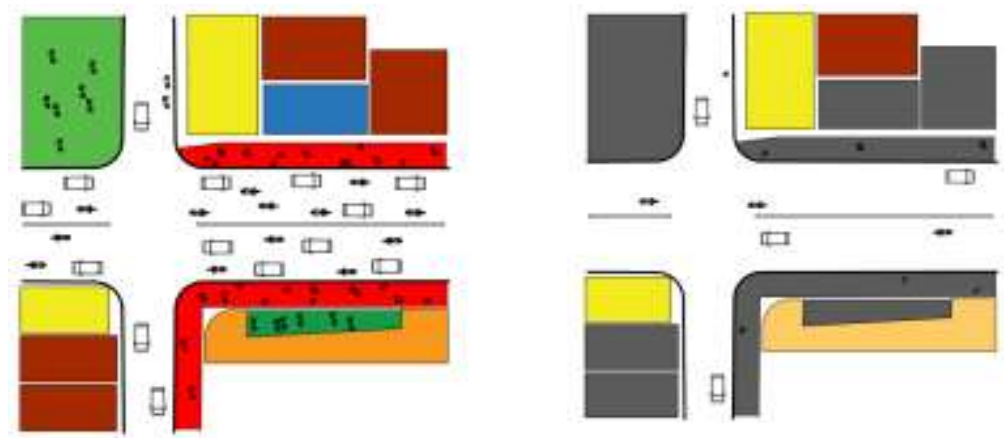

Fig. 20: Before and after scenario of COVID-19 in Connaught Place Source: Author 


\section{Tracing the Impact}

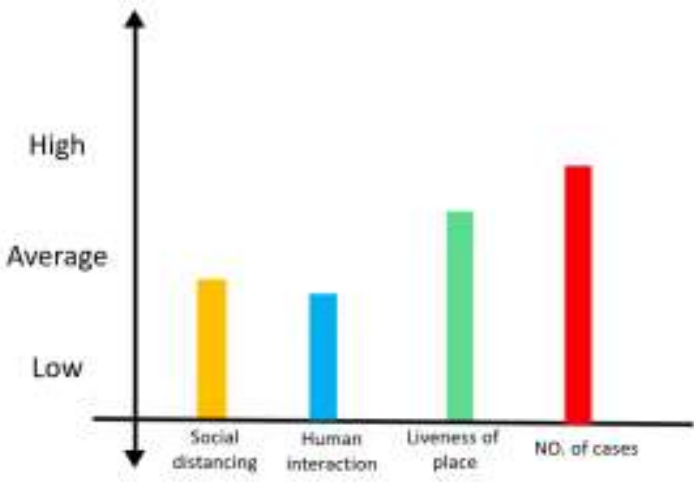

Compact Urban structure

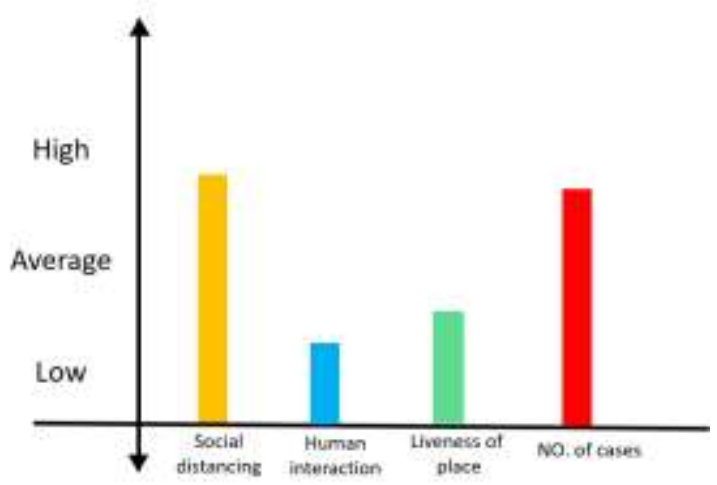

Standard Urban structure

Fig. 21: Chart showing a comparative intensity of social distancing, human interaction, liveness of place and no. of cases in compact and standard urban structure.

Source: Author

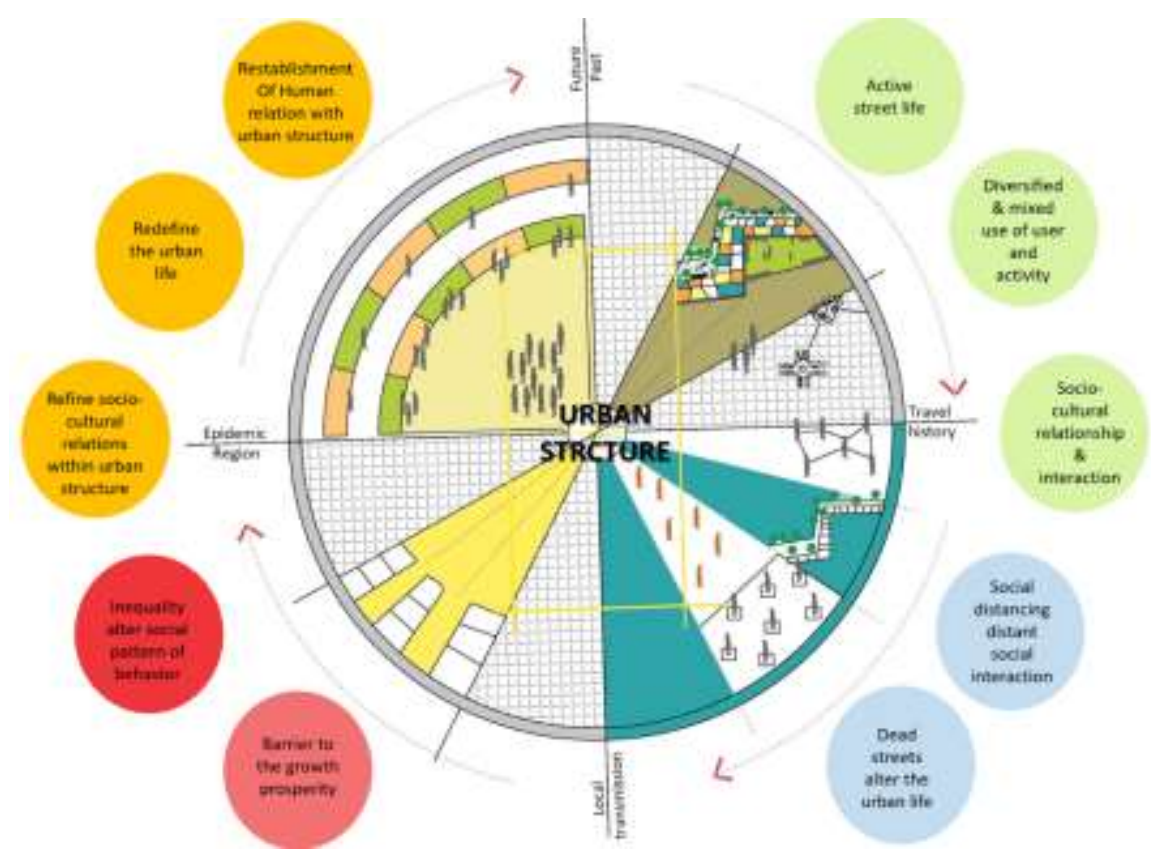

Fig. 22: Transforming quarters of Delhi during covid-19 Source: author

Figure 22: Represents different quarters of covid-19 phases and their impact on urban structure in Delhi. Last quarter intimates towards a resilient future of Delhi with attributes of humanized city. It encourages to look beyond immediate COVID-19 crisis to re-establish the relation between urban structure and human aspects of city. 


\section{Check your activity : On-line questionnaire for data recording}

1. Tick among the following urban structure in which you live?
a. Compact urban structure
b. Standard urban structure

2. Tick among the following options as your intermediate response during pandemic?
a. Face to face contact
b. Secondary contact
c. Online approaches
d. Informality

3. Describe degree of engagement into social activities you faced during COVID-19
a. Engaged
b. Not engaged
c. Actively disengaged

4. Describe the pattern of social disconnection you followed?
a. Isolation
b. Low interaction
c. Average interaction
d. High interaction

\section{Towards a New Paradigm of Humanized Urban Structure}

With COVID-19 Pandemic in place, the urban structures of the Delhi need to get a strategic direction and approaches for growth in a manner acceptable and supported by the people. The pandemic has thrown major challenges in order to balance between people's aspirations and resultant urban fabric. This can be deciphered from different perspectives which nevertheless converge to become a set of shared values with a standard and compact urban structure.

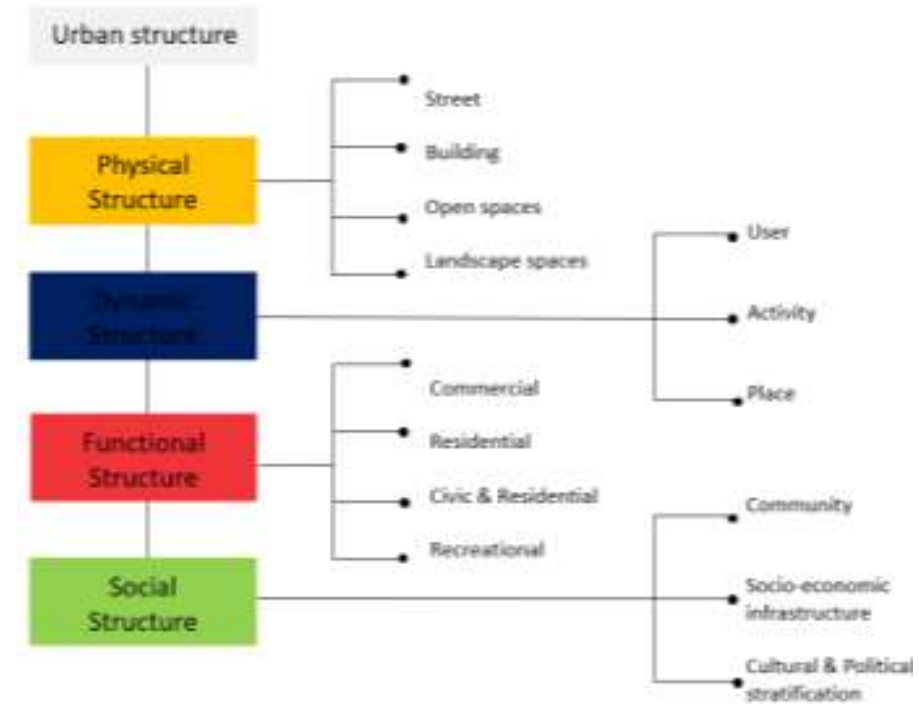

Fig. 23: Humanized urban structure Source: author 


\section{Conclusion}

The COVID-19 Pandemic has transformed the quality of life. The dilemma made people has resulted in a deterioration of the humanizing aspects of the urban structure within the city of Delhi. It is a general observation that, people in Delhi are carving and deriving their own ways to overcome this pandemic depending upon the prototypes of urban structures. Initially, the compact urban structure was under a huge threat of infection spread because of the high density and compact fabric. However, gradually, the standard urban structure was becoming the epicenter of community infection spread. Thus, the prototypes of urban structure contribute in shaping a humanizing attribute of the city along with people's participation, as people from the close-knit group managed to overcome the pandemic.

the contrasting context of Chandani Chowk and Connaught Place in Delhi during the pandemic suggests that only physical attributes of urban structures (street, open space, buildings) in isolation may not govern what humanization is, but it should also integrate with dynamic, functional and social structure. The need of time demands a newer definition of "humanized urban structure". To achieve it, we must integrate the imperative elements of identity, social integration, flexibility and place-making which may contribute to a higher degree of humanization. The notion of a humanized urban structure addressing to a high intervention of physical, dynamic, functional and a social structure will help to balance the knot between these: a) sphere of aspiration of people from urban structures and b) sphere of resultant from urban structure.

This paper proposed an integrated framework for a humanized urban structure in order to re-establish the relationship between urban structure and humanized city. Further, the research may contribute in formulating a qualitative and quantitative value systems for the derived imperative elements of humanized urban structure.

\section{References}

Bork-Hueffer (2014) 'Intra-urban and Interurban Quality of Life Approaches'.

Gehl, J. (2010) Cities for people, Island Press, Washington DC.

Giarratani, EMHAF (2020) 'An Introduction to regional economics', ULS.

Hindu, T. (2020) 'Aam Aadmi Mohalla Clinics', The Hindu, p. 1.

Llewelyn-Davies (2000) Urban Design Comoendiun, English Partnerships \& Housing Coporation, U.K, 2000, London.

Park, RE, Burgess, EW \& McKenzie, RD 1925, 'The City', p. 1.

Public spaces, Public life and COVID-19, Gehl -Copenhagen city 